\title{
Estrogen Receptors are Present in Neocortical Transplants
}

\author{
Erik B. Pedersen ${ }^{1,2}$, Joan A. O'Keefe ${ }^{1}$, Robert J. Handa ${ }^{1}$ and Anthony J. Castro ${ }^{1}$ \\ ${ }^{1}$ Department of Cell Biology, Neurobiology and Anatomy \\ Loyola University Stritch School of Medicine \\ Maywood, IL 60153, USA \\ and \\ ${ }^{2}$ PharmaBiotec, Institute of Neurobiology \\ University of Aarhus \\ DK-8000, Aarhus C, Denmark
}

\section{SUMMARY}

Fetal neocortical tissue was grafted into neocortical lesion cavities made in newborn rats. After two weeks survival, in vitro binding of $\left[{ }^{3} \mathrm{H}\right]$ estradiol to cytosolic preparations provided evidence of estrogen receptors within the transplants. The observed high levels correspond to previous work demonstrating elevated estrogen receptor levels during the first postnatal week in the rat cerebral cortex.

\section{KEY WORDS}

neural graft, newborn, cortex lesion, rat

Fetal, neocortical tissue grafted into cortical lesion cavities in newborn rats will survive and form extensive afferent and efferent connections with the host brain $/ 3,4,6-9,12,13,22,24,25 /$. These findings combined with other studies of transplant electrophysiology $15,17,21 /$, neuropeptide content /11/ and blood-brain barrier for-

\footnotetext{
Reprint address:

Erik Bo Pedersen

PharmaBiotec

Institute of Neurobiology

University of Aarhus

DK-8000, Aarhus C

Denmark
}

mation /26/ demonstrate that such transplants develop and retain many features of normal cortex. In order to examine transplant characteristics further, the present study was initiated to examine the estrogen receptor (ER) content of neocortical grafts. These results are derived from a larger ongoing study concerning the ontogeny of ER in the developing cerebral cortex as well as in intracerebral transplants of neocortical, hippocampal and hypothalamic tissue.

Thirty-two Sprague-Dawley rats with neocortical transplants were used in this study. They were derived from a continuing series of experiments demonstrating a $90 \%$ neocortical transplant survival rate. According to routine methods described previously $/ 3,7 /$, blocks of fetal (embryonic day 14-15) presumptive sensorimotor cortex were grafted into corresponding neocortical lesion cavities in newborn (postnatal day 0-1) rats. Lesion cavities were made by aspiration immediately before grafting. Dams for donor animals were anesthetized with sodium pentobarbital $(50 \mathrm{mg} / \mathrm{kg})$ and newborn pups to be used as graft recipients were anesthetized by hypothermia. Fourteen days after transplant surgery host animals were killed by decapitation and their brains removed immediately, placed on an ice cold brass plate and sliced coronally on either side of the transplant with the aid of a surgical microscope. Being careful not to include host tissue, a wedge of transplant tissue was dissected free. One $\mathrm{mm}$ punch samples of the contralateral homotypic cortex were also taken. The samples from 2 animals were pooled and the ER content of these pooled 
samples $(n=14)$ was quantified according to a modification of MacLusky et al. /16/ as previously described /18/. Four animals with transplants were killed by anesthetic overdose and perfused with $4 \%$ paraformaldehyde. The brains from these animals were cut at $40 \mu \mathrm{m}$ and stained with cresyl violet for routine histology.

Measurable ER levels were consistently found in the transplants. These levels $(8.84 \pm 2.8$ $\mathrm{fmol} / \mathrm{mg}$ protein) were significantly higher $(p<0.01)$ than those found in the contralateral homotopic cortex $(1.63 \pm 0.30 \mathrm{fmol} / \mathrm{mg}$ protein) (Fig. 1). Saturation analysis of $\left[{ }^{3} \mathrm{H}\right]$-estradiol binding revealed an apparent dissociation constant $\left(\mathrm{K}_{\mathrm{d}}\right)$ of $6.55 \times 10^{-10} \mathrm{M}(\mathrm{n}=2)$ for the neocortical grafts. These values correspond to those previously reported for the normal neocortex $/ 18 /$. Histologically, the transplants appeared well integrated within the host cortex and displayed the characteristic transplant organization with whorls and bands of cells found in previous studies.

The high ER levels found in the cortical transplants do not appear to represent a deviation from normal values. When considered in terms of their 1 week theoretical age (i.e., transplanted at E1415 and sacrificed 2 weeks later), the observed ER values correspond to the high levels found in normal cerebral cortex at this postnatal age /16, 18/. Related studies of perinatal neocortical tissue grafted into the cerebral cortex of young adult rats demonstrated normal concentrations of muscarinic receptors at 6-8 weeks post grafting $/ 15 /$. In contrast, abnormally high levels of bombesin and vasoactive intestinal peptide (VIP) receptors were found in long-term surviving neocortical grafts placed into the third ventricle of adult rats $/ 14 /$. These high values were interpreted in terms of a possible relationship to transplant growth and vascularization.

The presence of functional estrogen receptors in hypothalamus-preoptic area grafts /19/ suggests that such receptors found in our developing neocortical grafts may also be functional. Estrogen receptors in the developing nervous system, especially those located in areas mediating reproductive functions, are clearly involved in morphological and functional sexual differentiation. Cerebral cortical ER may also be involved in this process given the evidence for sex differ-

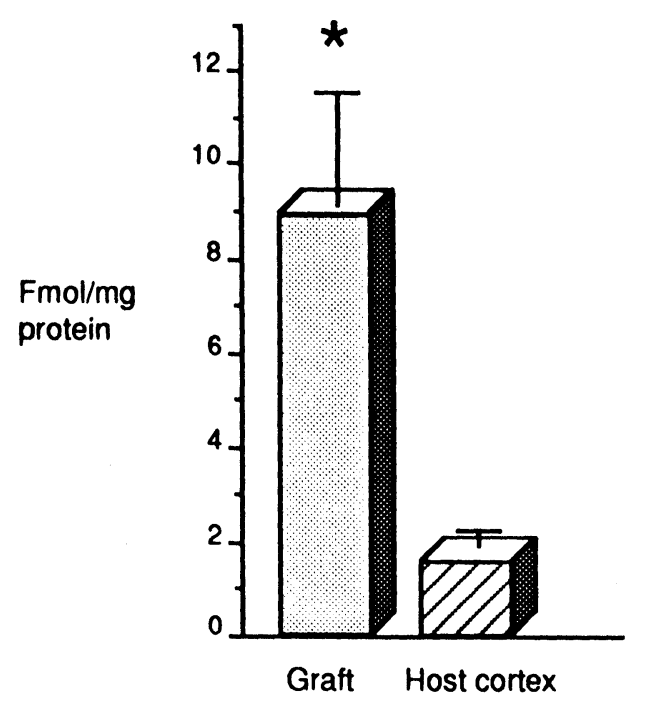

Fig. 1: Estrogen receptor levels found in neocortical grafts and in the contralateral homotopic host cortex. $\left({ }^{*} \mathrm{p}<0.01\right.$; Student's t-test)

ences in certain cognitive functions /1/. Estrogen administration at birth has been shown to increase cortical myelination $/ 10$ / as well as enhance neurite outgrowth from cerebral cortical and hippocampal $/ 2,27 /$ neurons in vitro. These data support a role for estrogen as a trophic factor underlying sex differences in cerebral cortical functions. The rather widespread distribution of ER MRNA in the adult brain /23/ suggests its participation in many other neural activities.

As estrogen appears to play an important role in several basic neural functions, our finding of estrogen receptors in neocortical grafts adds to a growing body of literature suggesting that grafted fetal neocortex will continue to develop and assume the characteristics of normal cortical tissue and become functionally integrated with the host nervous system. In this regard, electrophysiological studies demonstrated the integration of cortical grafts into the host afferent system by showing transplant unit activity evoked by peripheral stimulation $/ 5,17 /$. These results correspond to anatomical findings showing transplant afferents from the thalamus and several other areas of the host brain $/ 4,6,8,9,12 /$. Transplant efferents to the contralateral neocortex, thalamus, striatum, pons and spinal cord have also been reported $/ 3,7,13$, 22, 24, 25/. Electrophysiological studies confirm 
that transplants project to the thalamus and medullary pyramid $/ 17,21 /$. Although less dense than normal, these connections generally resembled normal connectivity patterns. Behavioral studies demonstrating the recovery of cortical lesion induced motor deficits by neocortical grafts reflect this host-transplant integration $/ 20 /$.

In conclusion, our findings of high ER content in developing neocortical transplants correspond to the transiently high levels found in the intact newborn cortex. These findings support previous anatomical, electrophysiological and behavioral studies which suggest the presence of normal tissue specific characteristics in neural transplants.

\section{ACKNOWLEDGEMENTS}

Supported by NIH Grant NS13210, the Danish Foundation for the Advance of Medical Science, The Lundbeck Foundation and a Potts Foundation Award.

\section{REFERENCES}

1. Beatty WW. Gonadal hormones and sex differences in nonreproductive behaviors in rodents: organizational and activational influences. Hormones Behav 1979; 12: 112-163.

2. Blanco GB, Diaz H, Carrer HF, Beauge L. Differentiation of rat hippocampal neurons induced by estrogen in vitro; Effects on neuritogenesis and Na,K-ATPase activity. J Neurosci Res 1990; 27:47-54.

3. Castro AJ, Tønder N, Sunde N, Zimmer J. Fetal cortical transplants in the cerebral hemisphere of newborn rats. A retrograde fluorescent analysis of connections. Exp Brain Res 1987; 66: 533-542.

4. Castro AJ, Tønder N, Sunde N, Zimmer J. Fetal neocortical transplants grafted to the cerebral cortex of newborn rats receive afferents from the basal forebrain, locus coeruleus and midline raphe. Exp Brain Res 1988; 69: 613-622.

5. Castro AJ, Hogan TP, Sørensen JC, Klausen BS, Danielsen EH, Zimmer J, Neafsey EJ. Heterotopic neocortical transplants. An anatomical and electrophysiological analysis of host projections to occipital cortical grafts placed into sensorimotor cortical lesions made in newborn rats. Dev Brain Res 1991; 58 : 231-236.

6. Castro AJ, Sørensen JC, Tønder N, Bold L, Zimmer J. Fetal neocortical transplants grafted into cortical lesion cavities made in newborn rats receive multiple host afferents. A retrograde fluorescent tracer analysis. Restor Neurol Neurosci 1989; 1: 13-23.

7. Castro AJ, Zimmer J, Sunde NA, Bold EL. Transplantation of fetal cortex to the brain of newborn rats: A retrograde fluorescent analysis of callosal and thalamic projections from transplant to host. Neurosci Lett 1985; 60: 283-288.

8. Chang F, Steedman JG, Lund RD. Embryonic cerebral cortex placed in the occipital region of newborn rats makes connections with the host brain. Dev Brain Res 1984; 13: 164-166.

9. Chang FF, Steedman JG, Lund RD. The lamination and connectivity of embryonic cerebral cortex transplanted into newborn rat cortex. J Comp Neurol 1986; 244: 401-411.

10. Curry JJ, Heim L. Brain myelination after neonatal administration of oestradiol. Nature 1966; 209: 915916.

11. Ebner FF, Olschowka JA, Jacobowitz DM. The development of peptide-containing neurons within neocortical transplants in adult mice. Peptides 1984; 5 : 103-113.

12. Floeter MK, Jones EJ. Connections made by transplants to the cerebral cortex of rat brains damaged in utero. J Neurosci 1984; 4: 141-150.

13. Floeter M, Jones E. Transplantation of fetal postmitotic neurons to rat cortex: Survival, early pathway choices and long-term projections of outgrowing axons. Dev Brain Res 1985; 22: 19-38.

14. Getz RL, Moody TW, Rosenstein JM. Neuropeptide receptors are present in fetal neocortical transplant. Neurosci Lett 1987; 79: 97-102.

15. Hohmann CF. Expression of cholinergic markers in transplants of immature mouse neocortex into adult mouse parietal cortex. Anat Embryol 1989; 180: 535 541.

16. MacLusky N, Chaptal C, McEwen B. The development of estrogen receptor systems in the rat brain and pituitary: postnatal development. Brain Res 1979; 178: 143-160.

17. Neafsey EJ, Sørensen JC, Tønder N, Castro AJ. Fetal cortical transplants into neonatal rats respond to thalamic peripheral stimulation in the adult. An electrophysiological study of single-unit activity. Brain Res 1989; 493: 33-40.

18. O'Keefe JA, Handa RJ. Transient elevation of estrogen receptors in the neonatal rat hippocampus. Dev Brain Res 1990; 57: 119-127.

19. Paden CM, Gerlach JL, McEwen BS. Estrogen and progestin receptors appear in transplanted fetal hypothalamus-preoptic area independently of the steroid environment. J Neurosci 1985; 5: 2374-2381.

20. Plumet J, Cadusseau M, Roger M. Fetal cortical transplants reduce motor deficits resulting from neonatal damage to the rat's frontal cortex. Neurosci Lett 1990; 109: 102-106.

21. Porter LL, Cedarbaum JM, O'Leary DDM, Stanfield $\mathrm{BB}$, Asanuma $\mathrm{H}$. The physiological identification of pyramidal tract neurons within transplants in the ros- 
tral cortex taken from the occipital cortex during development. Brain Res 1987; 436: 136-142.

22. Santacana $\mathbf{M}$, Heredia $M$, Valverde $\mathbf{F}$. Transplant connectivity in the rats cerebral cortex. A carbocyanine study. Dev Brain Res 1990; 56: 217-222.

23. Simerly RB, Chang C, Muramatsu M, Swanson LW. Distribution of androgen and estrogen receptor mRNA-containing cells in the rat brain: an in situ hybridization study. J Comp Neurol 1990; 294: 76-95.

24. Sørensen JC, Klausen B, Castro AJ, Zimmer J. Efferent connections of fetal cortical transplants placed in frontal neocortical lesions of newborn rats demonstrated with PHA-L axonal tracing. 1991; in press.
25. Stanfield BB, O'Leary DDM. Fetal occipital cortical neurones transplanted to the rostral cortex can extend and maintain a pyramidal tract axon. Nature (Lond) 1985; 313: 135-137.

26. Swenson R, Shaw P, Alones V, Kozlowski G, Zimmer J, Castro A. Neocortical transplants grafted into the newborn rat brain demonstrate a blood-brain barrier to macromolecules. Neurosci Lett 1989; 100: 35-39.

27. Toran-Allerand CD, Ellis L, Pfenninger KH. Estrogen and insulin synergism in neurite growth enhancement in vitro: mediation of steroid effects by interactions with growth factors? Dev Brain Res 1988; 41: 87-100. 

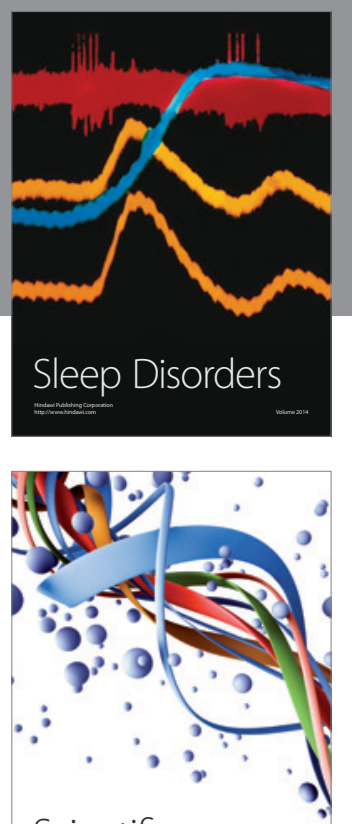

Scientifica
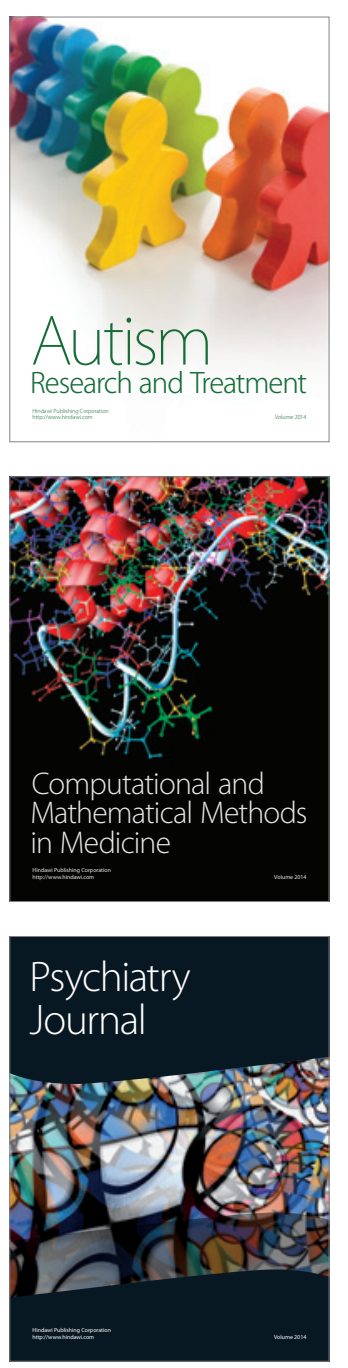
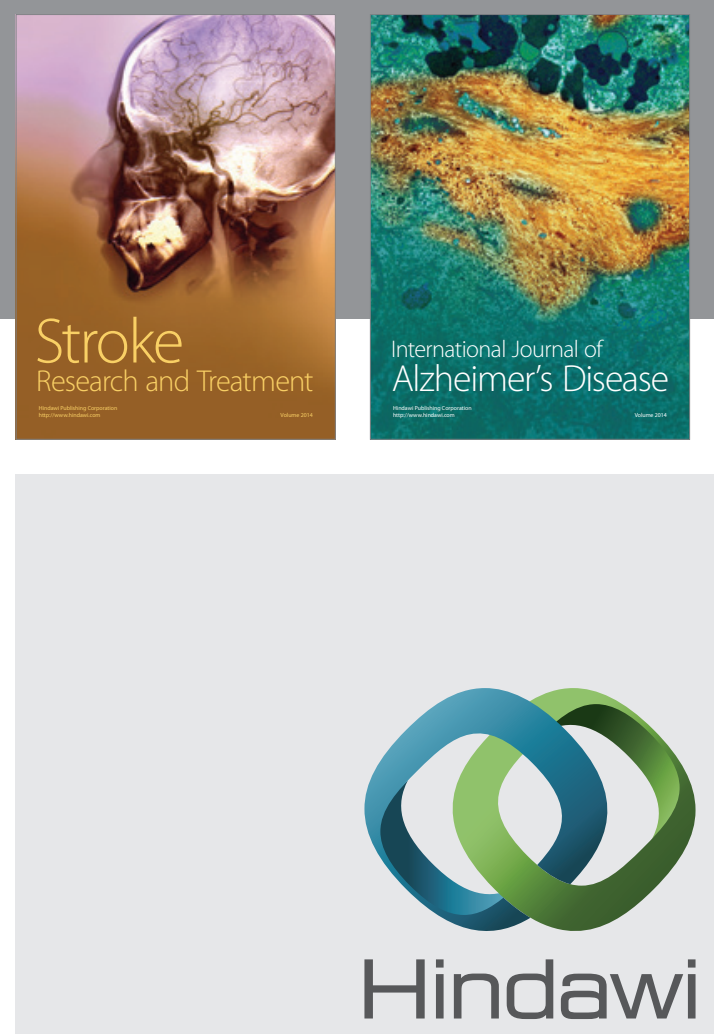

Submit your manuscripts at

http://www.hindawi.com
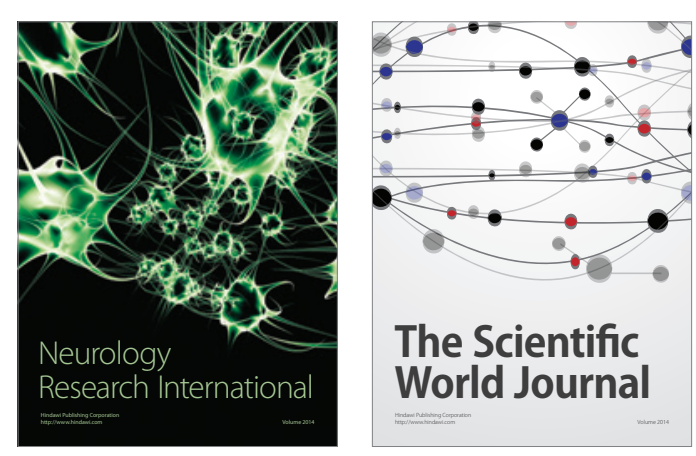

The Scientific World Journal

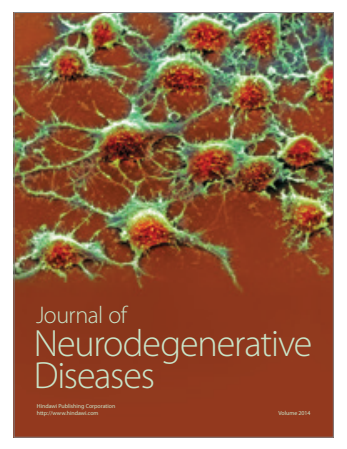

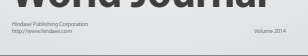

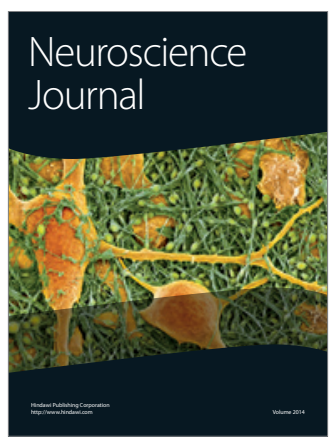

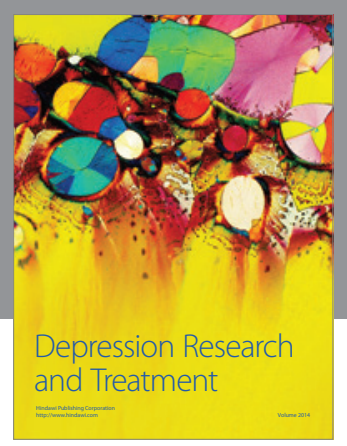
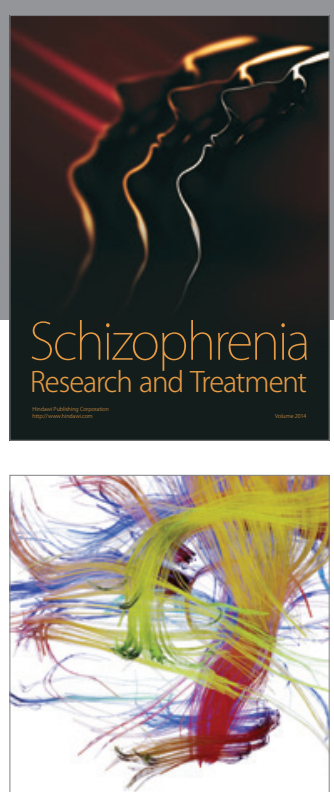

Brain Science

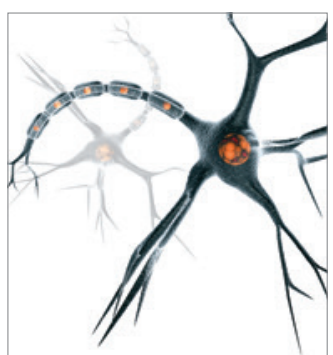

Neural Plasticity
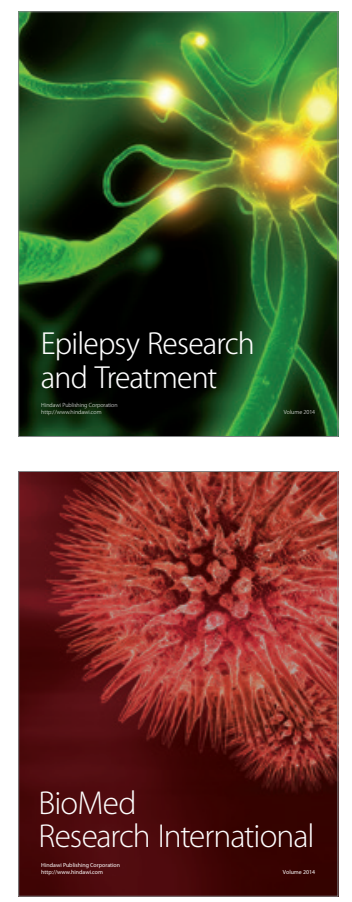

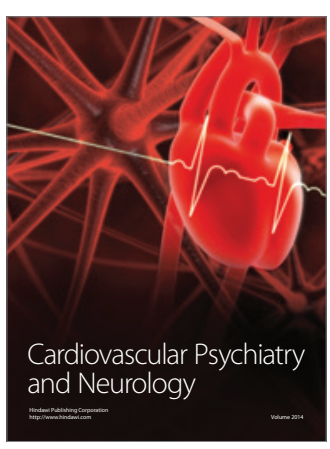

Parkinson's

Disease
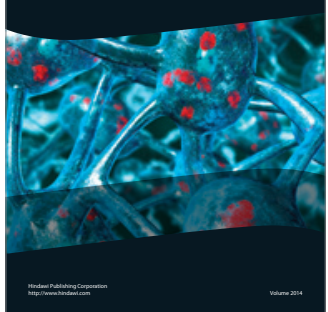